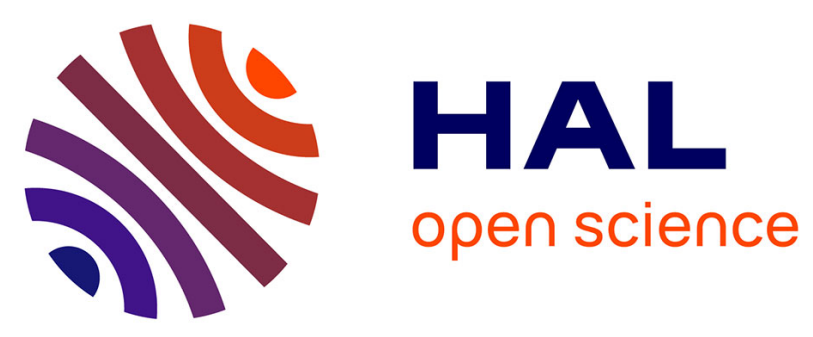

\title{
The management of ductal intraepithelial neoplasia (DIN): open controversies and guidelines of the Istituto Europeo di Oncologia (IEO), Milan, Italy
}

Gabriel Farante, Stefano Zurrida, Viviana Galimberti, Paolo Veronesi, Giuseppe Curigliano, Alberto Luini, Aron Goldhirsch, Umberto Veronesi

\section{To cite this version:}

Gabriel Farante, Stefano Zurrida, Viviana Galimberti, Paolo Veronesi, Giuseppe Curigliano, et al.. The management of ductal intraepithelial neoplasia (DIN): open controversies and guidelines of the Istituto Europeo di Oncologia (IEO), Milan, Italy. Breast Cancer Research and Treatment, 2010, 128 (2), pp.369-378. 10.1007/s10549-010-1124-4 . hal-00615375

\section{HAL Id: hal-00615375 https://hal.science/hal-00615375}

Submitted on 19 Aug 2011

HAL is a multi-disciplinary open access archive for the deposit and dissemination of scientific research documents, whether they are published or not. The documents may come from teaching and research institutions in France or abroad, or from public or private research centers.
L'archive ouverte pluridisciplinaire HAL, est destinée au dépôt et à la diffusion de documents scientifiques de niveau recherche, publiés ou non, émanant des établissements d'enseignement et de recherche français ou étrangers, des laboratoires publics ou privés. 


\section{The management of Ductal Intraepithelial Neoplasia (DIN): Open controversies and guidelines of the Istituto Europeo di Oncologia (IEO), Milan, Italy.}

Running Head:

DIN: Open controversies and guidelines of the IEO, Milan, Italy.

Gabriel Farante ${ }^{l}$, Stefano Zurrida ${ }^{1-4}$, Viviana Galimberti ${ }^{l}$, Paolo Veronesi ${ }^{1-4}$, Giuseppe Curigliano ${ }^{2}$, Alberto Luini $^{l}$, Aron Goldhirsch $^{2}$, Umberto Veronesi ${ }^{3}$

From the ${ }^{1}$ Division of Senology, ${ }^{2}$ Department of Medicine and ${ }^{3}$ Scientific Directorate of the European Institute of Oncology, IEO, Milan, Italy; and from the ${ }^{4}$ University of Milan, School of Medicine, Milan, Italy.

Authors' disclosures of potential conflicts of interest are found at the end of this article.

Corresponding author: Gabriel Farante, European Institute of Oncology, Via Ripamonti 435, 20141 Milan, Italy. e-mail: gabriel.farante@ieo.it 


\section{ABSTRACT}

Purpose. The management of ductal intraepithelial neoplasia(DIN) has substantially changed over the past 30 years, as its incidence has increased (from 2-3\% to more than 20\%), mainly due to the widespread use of mammography screening. This article describes not only the more widespread theoretical concepts on DIN but also the differences in the practical applications of the theory between different countries, different oncology specialists and different cancer centers.

Methods. Papers related to the international multicentric randomized trials and retrospective studies were analyzed. We include articles and papers published between 1993 and 2010 related to patients with DIN, and abstracts and reports from MEDLINE and other sources were indentified.

Results. The standard of care for DIN consists of a) breast conservative surgery (mastectomy is still indicated in large lesions -masses or microcalcifications- in about 30\% of cases); b) radiotherapy after conservative surgery and c) medical treatment in estrogen receptors $(E R)+$ patients. However, most studies have shown significant differences between theory and practical application. Moreover, there are differences regarding a) the indications of sentinel lymph node biopsy $(S L N B), b)$ the definition and identification of low risk DIN subgroups that can avoid radiotherapy $(R T)$ and tamoxifen and $c)$ the research into new alternative drugs in adjuvant medical therapy.

Conclusion. A general agreement on the best management of DIN does not exist as yet. New large trials are needed in order to define the best management of DIN patients which is (in most respects) still complex and controversial.

Keywords: ductal intraepithelial neoplasia - breast cancer - surgery - radiotherapy - medical treatment new agents - 


\section{Introduction}

DIN, is the new acronym (corresponding to ductal intraepithelial neoplasia) that replaces the traditional definition of ductal carcinoma in situ (DCIS) of the breast. This is because some authors [1] found it difficult to accept the intraductal proliferation of tumor cells being defined as a malignant tumor and others [2-3] think that in these cases, the $\mathrm{N}$ and $\mathrm{M}$ categories should not be applied and that there is therefore no reason to keep them within the TNM classification, as "intraductal carcinoma".

The incidence of breast DIN has been progressively increasing; it currently represents $15-25 \%$ of all breast carcinomas and approximately $35 \%$ of those diagnosed only by mammography. For example, in the USA, DIN increased from $1.87 / 100.000$ in $1973-1975$ to $32.5 / 100.000$ in 2004 [4]. Being overall 10-year survival close to $100 \%$ of affected patients, the surgery and radiotherapy interventions employed are sometimes more aggressive for this condition than those used for invasive cancer [2].

Some aspects of DIN management are still controversial, as reported in studies across the United States and Europe [5-7] and in different areas within the United States [8]. These controversies are mainly due to the heterogeneity of its clinical presentation and of its biological and pathological characteristics.

\section{BIOLOGICAL FEATURES OF DIN}

DIN is characterised by multiple clinical-pathological and biological features which differentiate it from both normal breast tissue and other benign proliferative breast lesions. As hyperplastic lesions progress through ductal carcinoma in situ to invasive breast cancer, chromosomal alterations usually occur with gain or loss at multiple foci[9]. Estrogen receptors (ER) are usually expressed in more than $70 \%$ of DIN lesions. The HER2/neu proto-oncogene is over-expressed in roughly half of all DIN lesions but not in atypical hyperplasia[10]. The p53 tumor-suppressor gene is mutated in approximately $25 \%$ of all DIN lesions, but is rarely mutated in normal proliferative breast tissue [11]. The most dramatic changes in patterns of gene expression during breast tumorigenesis appear during the transition from normal tissue to DIN [12], which is biologically heterogeneous, with variable molecular features. The gene-expression profile of grade 3 (G3) DIN differs from that of grade 1 (G1) lesions and exhibits a greater overall genetic change from normal breast tissue[13-14]. A great majority of G1 DIN lesions are positive for estrogen receptors, and less than 
$20 \%$ exhibit overexpression of HER2/neu or p53 mutations. In contrast, overexpression of HER2/neu or p53 mutations[15] arise in more than 75\% of G3 DIN lesions, whereas only one quarter of them express ER[16]. DIN can be considered a step in the development of breast cancer in which most of the molecular changes that characterize invasive breast cancer are already present[17].

\section{MANAGEMENT OF DIN PATIENTS}

\section{Surgical Treatment}

Mastectomy is considered today an overtreatment in most DINs due to the biological and pathological features and also its high survival rate and low absolute risk of local recurrences (LR). However, mastectomy is still indicated in DIN patients with multicentricity, diffuse microcalcification or large palpable masses, as well as when there is an inability to obtain negative margins.

The main goal of surgical treatment for women with DIN is breast conserving surgery (BCS) [1820] particularly for those patients with small solid masses, mammographically-detected lesions, or limited microcalcification areas, and because it is a disease with an extremely high survival rate and low absolute risk of LR.

At present, mastectomy is performed in about 30\%, BCS without radiotherapy in about $30 \%$ and BCS followed by radiotherapy in about $40 \%$ in DIN patients [21-23].

One important issue in breast cancer surgery is that of surgical margins, mainly in DIN patients, since these lesions are typically vague masses, which often cannot be adequately seen or felt and, thus, the pathological sampling of margins is fairly random [24-25]. There are two currently-held concepts that meet with general agreement on this topic: the first is the evidence that wide surgical excision and negative margins of resection decrease the risk of LR in patients with mammographically-detected DIN treated with BCS and radiation[26]. The second concept is a general consensus that patients with positive margins show a significantly higher rate of LR than do patients with negative margins, regardless of irradiation or tamoxifen administration[27-28].

In practice, there are two opposite approaches to surgical margins in a DIN patient: the anatomical approach, for which a clear margin width (of at least $10 \mathrm{~mm}$ ) is more important than any other prognostic factor or subsequent adjuvant therapy[29-30]; and the biological approach, for which the pathological 
characteristics of the lesion (G, comedo-necrosis, etc) are decisive in decision-making related to surgery and radiotherapy.

The current treatment of "positive" or focally involved margins in DIN patients is re-excision. Results of the UK Sloane Project showed that in $30 \%$ of patients undergoing BCS for DIN, preoperative imaging underestimates the extent of disease resulting in a requirement for further surgery[31]. On the other hand, some authors suggest that re-excision may be avoided and satisfactory local control achieved by increasing the radiation dose to the tumour bed to at least $66 \mathrm{~Gy}[32]$.

Regarding the width of surgical margins, about ten years ago, the "Consensus on DCIS of Philadelphia" [19], and Silverstein et al[30] proposed $10 \mathrm{~mm}$ as a limit of oncological safety. Since then other authors proposed progressively smaller measures, i.e., 3mm[33-35], 2-3 mm[136-37], $2 \mathrm{~mm}[38-40]$ and $1 \mathrm{~mm}$ [41]. At the 2009 Saint Gallen International Experts Consensus, there was consensus in avoiding the need to insist on a large $($ e.g. $1 \mathrm{~cm})$ free margins[42].

The issue of surgical margins is closely related to another important issue in DIN patients: LR. The risk of LR for DIN after BCS is the main concern, because approximately $50 \%$ of the recurrences are invasive[43]. LR is rare after total mastectomy, while it is observed at a higher rate in patients treated with breast conservation, even if the impact of these LR on overall survival is small. LR after 10 years of followup in DIN patiens is about $1 \%$ when mastectomy is performed, $30 \%$ in case of BCS alone and about $10-15 \%$ when BCS is followed by radiotherapy[44].

An interesting study (with a four-decade-long follow up) of women with G1 DIN treated by biopsy alone from 1950 to 1968 reveals the natural history of this poorly understood breast cancer[45]. This study shows that even G1 DIN left without further treatment have a risk of LR and will eventually develop invasive carcinoma in the same site in $30 \%$ of cases within 15 years.

Most LR in patients undergoing BCS and radiation for DIN occur in the proximity of the primary tumor. Virtually all patients who develop a non invasive LR, and approximately $75 \%$ of those with an invasive LR, are long-term survivors after mastectomy[46]. The risk of LR for clinically-evident DIN is approximately twice that of mammographically-detected DIN[47]. However, the recurrences after BCS are today diagnosed at a very early stage and almost always treated successfully; for that reason, breast cancer 
mortality in these patients is very low, about $1 \%$ [48-49] and probably due to an underestimated histological evaluation.

Several prognostic factors (PF) influencing LR in DIN patients have been identified[21,28, 50-56]. The most important PFs are the following: a) High nuclear grade and/or necrosis (particularly extensive comedo-necrosis); b) Tumor size; c) Margin status; and d) young age. In this respect, a recent study observed that DIN in younger women is more often symptomatic, is more extensive and more often shows cancerization of lobules than DIN in older women, although it requires further studies to conclude if these features contribute to the higher local recurrence risk in young patients[54]. In fact, another analysis concludes that young age may be a smaller contributor to LR risk in DIN than previously suggested[55]. In order to organize the information about PF, Silverstein[56] developed the Van Nuys Prognostic Index (VNPI), (including tumor size, margin width, histological classification and age), to define three risk groups of patients. But this Index was criticized by most authors[24,36].

One important controversial topic in DIN patients is the management of the axilla. We have recently examined this point[57] observing that, before the sentinel lymph node biopsy (SLNB) era, axillary dissection $(\mathrm{AD})$ was a part of the standard surgical treatment for these patients. Thanks to this procedure, the status of the axillary lymph nodes was reported as metastatic between 1-2\%[34, 58-59]. A logical and consequent conclusion from these low percentages, would be that $\mathrm{AD}$ should never be indicated as first treatment in DIN patients. However, both in theory and in practice it happens the contrary[34,59-61]. In the light of these analyses, we can conclude that $\mathrm{AD}$ should no longer be performed as a first indication of treatment in patients with pure DIN and that $\mathrm{AD}$ should be considered in these cases an unnecessary overtreatment without any rational justification.

But not only is AD not necessary, neither should SLNB always be required. However, this is still controversial in DIN patients. In fact, for some authors SLNB should not, in general, be indicated[62]; for others, SLNB should always be carried out[63-64], and for others still, it should be performed only in certain specific and particular cases[65-68]. Major cancer centers agree that SLNB should be conducted a) always when mastectomy is performed [66,68-70]; b) with large lesions (masses or micro-calcifications) and G3 tumors[66-67]; c) after performing core or mammotome biopsies. In these cases, because an invasive ductal carcinoma can be found at the final pathological diagnosis after surgery: generally, this upstaging 
represents about $16-20 \%$ of these cases, with variations from $11-13 \%$ (in cases of either $\mathrm{T} 1$ or G1 lesions) to 36-45\%(in cases of extended or G3 lesions) [71-78].

The last question related to the management of the axilla in DIN patients is: should we perform AD in cases of positive SLNB in DIN patients, as we do in cases of infiltrating breast carcinoma? In the few cases published in the literature[63,68-70,78-81], in which AD was performed after an positive SLNB, in all cases but one $(67 / 68,98,5 \%)$ all the non-SLNs were negative and the SLN already biopsied was the only positive LN. That is why we conclude that in cases of DIN patients with a positive SLNB, AD should not be immediately performed except for only those cases that present mammary invasion on final pathologic evaluation.

Open questions remain regarding the significance of isolated tumor cells or micrometastases in the lymph nodes as well as the role SLNB plays in DIN with microinvasion[34,82].

\section{Radiation Therapy}

\section{External RT}

The role of radiotherapy in DIN patients with conservative treatment has been mainly defined by four randomized trials: the NSABP B-17[83], the EORTC 10853[84], the United Kingdom-Australia-New Zealand (UK-A-NZ) trials[85] and the Swedish study on women screened with mammography[86]. A recent review of these trials confirm the following results[87]: all four studies demonstrated that additional radiotherapy reduced the LR rate by about 50\%, with no effect on survival. Comparable reductions were seen for the risk of invasive and non invasive LR. Non-significant long term toxicity from radiotherapy was found. These trials were organized to discover whether radiation therapy decreases LR and this was something they clearly demonstrated.

The controversy is, instead, related if all DIN patients have to undergo RT. According to the $2009 \mathrm{St}$ Gallen Consensus[42], RT could be avoided in elderly patients and in those with G1 DIN and clearly negative margins. There are two aspects that are to be taken into consideration at the moment of performing RT in DIN: the margins of resection and the tumor grading. Regarding margins, the recent ECOG report[35] showed that a margin of $3 \mathrm{~mm}$ or wider could be an adequate width for only excision without irradiation (in 
G1-G2 DIN patients). Regarding tumor grading, clinicians agree that patients with high-grade DIN and with close margins benefit from adjuvant radiotherapy. However, there are controversies regarding the need for radiotherapy in patients with low-grade DIN which has been resected with wide (>10 mm) negative margins. Two prospective studies showed contradictory results: in the trial from the Dana-Farber Cancer Institute[8889], the omission of radiation therapy after wide excision alone resulted in a high cumulative LR rate of $12 \%$ at 5 years of follow-up in patients with G1 DIN. On the contrary, the EORTC 10850 trial showed that within the group of DIN, patients treated with BCS alone (with $26 \%$ of 10-year LR-free rate) in the subgroup G1 DIN after surgery alone, presented a risk of LR $<10 \%$ at 10 years' follow up[84].

In fact this is one of the more important controversies regarding the management of DIN patients: are all these patients candidates to receive RT after BCS? At the IEO in Milan, the answer to this question has been no, for more than a decade. In fact, RT is not administered to DIN patients with G1 or G2 without comedonecrosis. On the other hand, only last year, at least four significant papers (from the Saint Gallen Consensus[42], the ECOG trial [35], the Newport Consensus Conference III [90], and from the National Consensus Cancer Network [91]) suggested that some DIN patient sub-groups (i.e., G1 or G2 tumors without comedonecrosis, and other low-risk sub-grups) could not be candidates to receive RT after BCS.

Another open question is related to the use of a boost after RT in DIN patients. In a multicentric, retrospective study, Omlin et al [92] demonstrated that an RT boost decreases LR in patients <45 years of age. The ten-year relapse-free survival was $46 \%$ for patients not receiving any RT, $72 \%$ for patients with RT without boost and $86 \%$ for patients receiving RT including a boost, thus suggesting that an RT boost should be considered in addition to surgery for BCS in patients with DIN. A French multicentric randomized trial, the first study evaluating in young DIN patients the impact of a 16 Gy boost after 50 Gy delivered to the whole breast in 25 fractions and 33 days, has started inclusions recently[93].

\section{Intraoperative Radiotherapy (IORT).}

The standard course of current external RT after BCS for DIN, delivers a total dose of 50 Gy in daily fractions of 1.8/2 Gy without boost. Intraoperative Radiotherapy (IORT), instead, is an attractive new treatment, an accelerated partial breast irradiation (APBI), and offers a new approach to irradiate the breast directly during the surgery itself when BCS is performed. The recent Consensus Statement from the 
American Society for Radiation Oncology agreed that IORT can be used in some particular group of breast cancer patients[94], but there is no significant data of the use of APBI in DIN patients. The American Society of Breast Surgeons Registry Trial includes the largest published collection of DIN treated with APBI. In this series, four-year follow-up shows result similar to those with invasive cancer treated with APBI, as well as DIN treated with whole breast irradiation[95] In some cases with DIN, IORT is also used on the nipple-areola- complex (NAC) when a NAC-sparing mastectomy in performed. This is a new surgical procedure whose risks and complications are acceptable when compared to the traditional surgical treatment of breast cancer[96]. In some institutions, such as the IEO in Milan, the NAC-sparing mastectomy is associated with IORT (so-called E[1]LIOT, one shot of $16 \mathrm{~Gy}$ ) to the NAC[96]. In other centres, it is performed without IORT[97-98].

\section{Medical treatment}

Two known international trials studied tamoxifen effects after BCS and RT. One of them (NASBP B-24) [27], showed that tamoxifen reduces LR of DIN patients, whereas the other trial[85] did not demonstrate that advantage.

Currently, systemic therapy is related to ER status and is only considered for ER-positive patients. Barnes et al[99] found that most DIN lesions are ER-positive, especially in well and moderately differentiated G1 and G2 tumors, while a large fraction of G3 and comedonecrosis DIN lack or have less marked ER expression.

\section{Patients with ER-positive tumors}

The role of tamoxifen was addressed in the above- mentioned NSABP B-24 trial[27], reducing the number of overall breast cancer events by $37 \%$ (43\% in invasive and $31 \%$ in noninvasive breast cancer events). This overall reduction was secondary to a $31 \%$ decrease in the incidence rate of ipsilateral breast tumors $(\mathrm{p}=$ $0.02)$ and a $47 \%$ reduction in contralateral breast cancers $(\mathrm{p}=0.01)$. With regard to ER, there were $77 \%$ ERpositive patients and 23\% ER-negative patients. The reduction of all breast cancer events was 58\% for ERpositive patients (p. 0.0001) and $23 \%$ for ER-negative patients (p. 0.45) [83]. In women under 50 years of age, tamoxifen reduced the risk of ipsilateral breast tumors by $38 \%$ whereas in patients aged 50 and older the 
reduction was $22 \%$. On the other hand, tamoxifen was found to reduce the risk of recurrence in patients with both positive and negative margins. However, even with tamoxifen there were fewer local failures in the group with negative margins (22\%) than in the group with positive margins (44\%)[27]. The risk/benefit ratio should be considered in each patient: women undergoing BCS, premenopausal women, and postmenopausal histerectomized women are likely to achieve the greatest benefit from tamoxifen.

A possible alternative for low-risk patients could be the use of low-dose tamoxifen, as shown by three IEO papers: firstly, Decensi et al. [100], demonstrated that the effects on Ki-67 expression of lower doses of tamoxifen ( $1 \mathrm{mg}, 5 \mathrm{mg} /$ day) were proven to be comparable to those achieved with the standard dose (20mg/day), although the effects on blood biomarkers were variable. Secondly, the cases of low-dose tamoxifen were confirmed in a randomized dose-ranging trial in hormone replacement therapy (HRT) users. A dose of $5 \mathrm{mg} /$ day was the most effective and was selected for a phase III trial in HRT users; this dose modulates favourably biomakers of breast carcinogenesis and cardiovascular risk, with no increase of endometrial proliferation and menopausal symptoms[101]. Thirdly, low doses of tamoxifen were associated to a lower incidence of recurrence in patients with ER-positive and HER-2-negative disease[21].

At present two selective estrogen receptor modulators, tamoxifen and raloxifene, are approved in the US for reduction of breast cancer risk in high-risk women. Tamoxifen, but not raloxifene, is also approved for adjuvant therapy in patients treated with breast-conserving excision and radiation for DIN. In the NSABP-P2 prevention trial, raloxifene was as effective as tamoxifen in reducing the risk of Infiltrating Breast Cancer (IBC), but was 30\% less effective than tamoxifen in reducing the risk of DIN[102].

Interestingly, the UK-A-NZ trial on adjuvant tamoxifen and radiation therapy in DIN patients found that tamoxifen did not significantly reduce the overall event rate or the rate of IBC events, but did reduce the overall rate of DIN (hazard ratio, $0.58 ; 95 \% \mathrm{CI}, 0.49$ to $0.96 ; \mathrm{P}=.03$ ) [85]. The different results may be a consequence of a different patient population: the NSABP B-24 study had a higher proportion of patients younger than $50(34 \%$ vs $10 \%)$, and tamoxifen was associated with a greater risk reduction in this age group[27].

On the other hand, the impact of the NSABP B-24 results on tamoxifen use in patients with DIN was evaluated and it was reported that the overall acceptance was $41 \%$ [103]. That's why, considering $a$ ) this low acceptance, $b$ ) the controversy regarding tamoxifen benefit in ER-negative DIN and $c$ ) the side effects 
related to therapy with tamoxifen (that might not be acceptable to an otherwise healthy women), other agents should be evaluated for adjuvant therapy in patients with DIN.

The aromatase inhibitors (AI) group[104] reduces the risk of contralateral breast cancer by 50\% when compared with tamoxifen in adjuvant breast cancer trials. Two trials are currently evaluating the role of the aromatase inhibitor anastrozole as adjuvant therapy in patients with DIN: the NSABP B-35 and the International Breast Cancer Intervention Study-II. Furthermore, non-endocrine agents should also be considered, especially for high-grade DIN, including COX-2 inhibitors, retinoids and tyrosine kinase inhibitors such as trastuzumab[23].

\section{Patients with ER-negative tumors}

Patients with ER-negative DIN are not candidates for tamoxifen. However, a preventive strategy is needed to reduce the incidence of ER-negative tumors, which contribute to breast cancer-related mortality. Some studies suggest that the administration of COX-2 inhibitors to patients with ER-negative DIN may represent such a strategy[105-106]. The association of COX-2 with HER-2 expression, is a surrogate marker of an aggressive DIN phenotype and links non-estrogen growth factor-signaling pathways with COX-2 overexpression. There is no evidence that herceptin, the antibody approved for the treatment of HER-2positive invasive breast cancer, is beneficial for patients with DIN (even if the lesion is HER-2 positive). At present, Lapatinib, an approved oral agent for HER-2-positive breast cancer, is under investigation for DIN[107]. There is an ongoing non-randomized clinical trial in the USA to find out whether a single dose of the drug Herceptin (trastuzumab) administered before surgery kills cancer cells or slows the growth of cancer cells in women who have DIN, and to evaluate the effect of a single dose of Herceptin on the apoptotic index of Her-2/neu-overexpressing DIN[108]. So, COX-2 inhibitors and trastuzumab could play a role in preventing invasive breast cancer in patients with ER-negative DIN[109] .

\section{New agents and new strategies for medical treatment?}

The biological alterations controlling DIN proliferation are not clear. The fact that antiestrogens are not effective in ER-negative breast cancers, suggests that other factors are promoting proliferation in ERnegative DIN. Mutated or over expressed tyrosine kinases are frequently associated with tumor development. 
Epidermal growth factor receptor (EGFR) is a receptor tyrosine kinase (TKI) that is involved with mitogenesis and is expressed in ER-negative DIN. It has been hypothesized that EGFR is central in driving proliferation in ER-negative/EGFR-positive DIN[110]. Preclinical studies have demonstrated that EGFRTKI therapy reduces proliferation and increases apoptosis in the epithelium, and, either alone or combined with antiestrogen therapy, EGFR-TKI may represent a novel form of chemoprevention. Clinical trials should investigate evidence that breast cancers that have become tamoxifen-resistant use the EGFR signalling pathway which would suggest that the combination of tamoxifen and Iressa would be potent at chemopreventing cancer[111].

Preclinical studies have involved the development of genetically engineered mice (GEMs) to investigate cancer prevention. GEMs harbour activated oncogenes and/or inactivated tumour-suppressor genes that predispose them to develop cancer[112]. These studies provide evidence of the great potential of vaccines to induce prevention of cancer and demonstrate that a vaccine-alerted immune system effectively blocks the carcinogenesis process driven by the overexpression of specific oncogenes[112-114]. In GEMs that are transgenic for the rat HER2 oncogene, mammary and salivary carcinogenesis is driven by HER2receptor expression, whereas down-modulation or loss of the receptor blocks tumor progression[115-117]. As preventive vaccines operate during the early phases of carcinogenesis, effective inhibition of the HER2 receptor arrests the whole process and renders the selection of HER2-receptor-loss variants unlikely. Preclinical data available in GEMs models cannot be directly translated to humans for preventive treatments; these require more attention since the plan would be to vaccine a healthy individual.

Vaccination against selected oncoantigens of healthy people who have a specific genetic risk of cancer, who have been exposed to an exogenous carcinogen, or who bear multifocal pre-neoplastic lesions would provide the most appropriate scenario. New clinical trial targeting HER-2/neu using a dendritic cell vaccine in a neoadjuvant trial for treatment of DIN patients are ongoing[118]. Starting from the hypothesis that trastuzumab will have substantial activity against DIN, some trials are studying the use of trastuzumab a) after breast-conserving surgery with negative margins, for patients with HER-2/neu-overexpressing DIN (NSABP phase III randomized trial) [23]; b) before surgery as neoadjuvant treatment in DIN patients (at the MDAnderson) [23] and c) some studies used trastuzumab during breast irradiation[119] 


\section{MANAGEMENT OF DIN PATIENTS AT THE Istituto Europeo di Oncologia (IEO)}

Between June 1994 and December 2009, a total of 24,668 breast cancer patients were treated at the IEO, in Milan, Italy; 4,350 of these $(17,6 \%)$ were DIN patients. About $80 \%$ of these patients received BCS and $20 \%$ mastectomy, in accordance with the following IEO guidelines for the management of DIN patients.

\section{Guidelines for surgery}

The surgical decisions depend on the amount of breast tissue with DIN, the size of the breast, other health and physical factors and the patient's preferences.

\section{a. Indications for breast conservative surgery (BCS):}

BCS is performed in cases of detected mammographically DIN lesions or palpable masses, without evidence of multicentricity or diffuse malignant calcifications. The extent of DIN for BCS should be near 3-4 cm but this depends mainly on an appropriate cosmetic final result (the rate tumor/breast side should be considered). In cases of non-palpable lesions the procedure is as follows: a) for small or non-palpable masses or for clusters of microcalcifications, the surgical excision is guided by the ROLL (Radioguided Occult Lesions Localization), a technique developed at the IEO[120]; $b$ ) for extended or diffuse microcalcifications, the skin over the area of microcalcifications is mapped by the radiologist, and the surgeon takes into consideration the extension of the mapped area to decide if performing either BCS or mastectomy.

\section{b. Indications for mastectomy}

Mastectomy is performed in cases of a) large and extended DIN areas, in which BCS would create a bad final cosmetic result; b) multiple areas of DIN in the same breast, i.e., multicentricity or extended multifocality. The NAC-sparing mastectomy, with IORT (ELIOT) applied to the nipple areola complex is more often proposed. 
c. Breast reconstruction after mastectomy: When mastectomy is performed, immediate breast reconstruction is always proposed to the patient, via different techniques (expander, definitive prostheses or flap) depending on the size of the breast, the local situation, the possible contraindications and the wishes of the patient.

\section{d. Surgical treatment of recurrences:}

The decision to perform a new BCS or a mastectomy after a LR, depends on the cosmetic final results and the patient's opinion: both are important elements to be considered when making the decision. Regarding the width of surgical margins, the IEO considers $1 \mathrm{~mm}$ as a limit of oncological safety.

\section{e. Axillary management:}

AD is never indicated as a first surgical treatment in DIN patients. SLNB is only considered: $a$ ) in all cases of mastectomy; $b$ ) when there exists a strong doubt of invasion or microinvasion (i.e., in cases of large solid lesions or diffuse microcalcifications) and $c$ ) after a DIN diagnosis by core or mammotome biopsy. If the SLNB is positive, AD should be performed only in cases with mammary invasion on final pathologic evaluation.

\section{Guidelines for radiotherapy}

DIN patients are divided into two groups based on the pathological features as follows: on the one hand, radiotherapy (50 Gy to the whole breast, without boost) is given to all patients with Grade 3 and with Grade 2 and comedonecrosis, considering that radiotherapy is more effective over cells in phase G2 of the cellular cycle. On the other hand, no radiotherapy after BCS is indicated in Grade 1 and Grade 2 in patients without comedonecrosis; in these cases, RT is considered an overtreatment.

\section{Guidelines for systemic treatment}

DIN patients are divided according to their ER status:

a. ER-positive patients: premenopausal and postmenopausal patients receive low-dose tamoxifen (20mg/week) or participate in the IBIS-2 trial, which has 2 arms: after quadrantectomy, Tamoxifen $20 \mathrm{mg} /$ day) vs Anastrazole (100mg/day); after mastectomy, Anastrazole (100mg/day) vs placebo. 
b. ER-negative patients: The standard for ER-negative both pre and postmenopausal patients is no treatment. As an alternative a randomized pilot study of pharmacoprevention is proposed to high risk patients. This study includes 150 patients divided into three groups, receiving during one year: a) Nimesulide (100mg/day), b) Sinvastatina (20mg/day) and c) placebo

\section{FINAL CONSIDERATIONS}

Data for irradiation in DIN patients are strong and consistent, after the results of the known randomized trials[83-86], while the recommendations for adjuvant tamoxifen must be reviewed in light of the differences in reported outcomes from two mentioned randomized trials[27,85]. Treatment with radiation and tamoxifen can reduce the risk of recurrence, including invasive recurrence, but for the overall population of patients with DIN, such risk reduction comes with the knowledge that most patients would be overtreated.

Moreover, some questions remain open and call for new international consensus and agreements, i.e.: a) Regarding surgery: Which margin width can be considered oncologically safe $(1 \mathrm{~mm}$ ? $3 \mathrm{~mm}$ ? 10 $\mathrm{mm}$ ?). Are micrometastasis in a SLNB of any clinical significance in DIN patients? Are macrometastasis in DIN patients responsible for long term axillary recurrences? Could macrometastasis be the only situation that justifies a complete axillary dissection? Is it necessary to perform a complete axillary dissection in cases of SLNB positivity in DIN patients? If not, why perform SLNB in this group of patients? b) Regarding radiotherapy: Which group of DIN patients does not need RT after BCS? Do young DIN patients benefit from the application of a boost after 50-Gy radiotherapy? Is RT really needed when there are safe margins of $10 \mathrm{~mm}$ or more, regardless of tumor size, nuclear grade and the presence or absence of comedo-necrosis? c) Regarding systemic therapy: Are collateral effects of tamoxifen justified in low-risk ER-positive DIN patients? How should ER-negative DIN patients be treated? What is the potential role of vaccines and Trastuzumab in cancer prevention (including DIN)?.

The variations on DIN management in practice, demonstrated, for example, by the ASTRO/ESTRO investigation[8], the UK Sloane Project [60]and the French experience[61] show that breast cancer 
professionals are not convinced about the optimal method to treat DIN patients. New large trials are needed in order to evaluate the best management of DIN which is in most respects still complex and controversial. 
AUTHORS' DISCLOSURE OF POTENTIAL CONFLICTS OF INTEREST: The authors indicate no potential conflicts of interest. ACKNOWLEDGEMEHNTS

The authors would like to thank Marina Nordiana Baruzzi and Maria Grazia Villardita for the preparation of the manuscript and William Russell-Edu for the MEDLINE research and editing. 


\section{REFERENCES}

1. Tavassoli FA (1998) Ductal carcinoma in situ: introduction of the concept of ductal intraepithelial neoplasia. Mod Pathol $11: 140-154$

2. Veronesi U, Boyle P, Goldhirsch A, et al (2005) Breast cancer. Lancet 365: 1727-1741

3. Veronesi U, Viale G, Rotmenz N, et al (2006) Rethinking TNM: Breast cancer TNM classification for treatment decisionmaking and research. Breast 15, 3-8

4. Virnig B, Tuttle T, Shamliyan T, et al (2010) Ductal carcinoma in situ of the Breast: a systematic review of incidence, treatment and outcomes. J Natl Cancer Inst 102: 170-178

5. Baxter NN, Virnig BA, Durham SB, et al (2004) Trends in the treatment of ductal carcinoma in situ of the breast. J Natl Cancer Inst 96: 443-448

6. Ernster VL, Barclay J, Kerlikowske K, et al (1996) Incidence of and treatment for ductal carcinoma in situ of the breast. JAMA 275: $913-918$

7. Ceilley E, Jagsi R, Goldberg S, et al (2004) The Management of Ductal Carcinoma In Situ in North America and Europe Results of a Survey. Cancer 101: 1958-1967

8. Katz SJ, Lantz PM, Janz NK, et al (2005) Patterns and Correlates of Local Therapy for Women With Ductal Carcinoma-In-Situ. J Clin Oncol 23: 3001-3007

9. Aubele MM, Cummings MC, Mattis AE, et al (2000) Accumulation of chromosomal imbalances from intraductal proliferative lesions to adjacent in situ and invasive ductal breast cancer. Diagn Mol Pathol 9: 14-19

10. Allred DC, Clark GM, Molina R, et al (1992) Overexpression of HER-2/neu and its relationship with other prognostic factors change during the progression of in situ to invasive breast cancer. Hum Pathol 23:974-979

11. Rudas M, Neumayer R, Gnant MFX, et al (1997) p53 Protein expression, cell proliferation and steroid hormone receptors in ductal and lobular in situ carcinomas of the breast. Eur J Cancer 33: 39-44

12. Luzzi V, Holtschlag V, Watson MA (2001) Expression profiling of ductal carcinoma in situ by laser capture microdissection and high-density oligonucleotide arrays. Am J Pathol 158: 2005-2010

13. Seth A, Kitching R, Landberg G, et al (2003) Gene expression profiling of ductal carcinomas in situ and invasive breast tumors. Anticancer Res 23: 2043-2051

14. Allred DC, Wu Y, Tsimelzon A, et al (2002) The progression of DCIS to IBC: a cDNA expression microarray study. Breast Cancer Res Treat 76: Suppl 1: S81-S81

15. Allred DC (2002) Biologic characteristics of ductal carcinoma in situ. In: Silverstein MJ, ed. Ductal carcinoma in situ of the breast. 2nd ed. Philadelphia: Lippincott Williams \& Wilkins, 37-48

16. Lampejo OT, Barnes DM, Smith P, Millis RR (1994) Evaluation of infiltrating ductal carcinomas with a DCIS component: correlation of the histologic type of the in situ component with grade of the infiltrating component. Semin Diagn Pathol 11: 215-222

17. Buerger H, Otterbach F, Simon R, et al (1999) Different genetic pathways in the evolution of invasive breast cancer are associated with distinct morphological subtypes. J Pathol 189: 521-526 
18. Fisher ER, Leeming R, Anderson S, et al (1991) Conservative management of intraductal carcinoma (DCIS) of the breast. J Surg Oncol 47: 139-147

19. Schwartz GF, Solin L, Olivotto I. et al (2000) Consensus Conference on the Treatment Classification of Ductal Carcinoma in Situ of the Breast, April 22-25, 1999. Cancer 68: 946-954

20. Silverstein MJ, Cohlan BF, Gierson ED, et al (1992) Ductal carcinoma in situ: 228 cases without microinvasion. Eur J Cancer 28: $630-634$

21. Guerreri-Gonzaga A, Botteri E, Rotmensz N et al (2009) Ductal Intraepithelial Neoplasia: Postsurgical out come for 1.267 woman cared for in one single Institution over 10 years. Oncologist 14: 201-212

22. Schmidt GL, Schmidt BD, Haffty BG (2006) Rationalization and regionalization of treatments for DCIS of the breast. Int $\mathbf{J}$ Radiat Oncol Biol Phys 65: 1397-1403

23. Kuerer HM, Albarracin C, Yang NT et al (2008) DCIS: State of the science and roadmap to advance the field. J Clin Oncol 27: $279-288$

24. Fisher ER, Dignam J, Tan-Chiu E et al (1999) Pathologic findings from the NSABP eight years update of Protocol B-17: Intraductal Carcinoma. Cancer 86: 429-438

25. Allred DC (2005) Ductal Carcinoma In Situ of the Breast: Pathologic and Biologic Perspectives. American Society of Clinical Oncology 2005 Educational Book $41^{\text {st }}$ Annual Meeting May 13-17: 75-79

26. Mirza NQ, Vlastos G, Meric F, et al (2000) Ductal carcinoma- in situ: Long-term results of breast conserving therapy. Ann Surg Oncol 7:656-664

27. Fisher B, Dignam J, Wolmark N, et al (1999) Tamoxifen in treatment of intraductal breast cancer: National Surgical Adjuvant Breast and Bowel Project B-24 randomized controlled trial. Lancet 353: 1993-2000

28. Bijker N, Peterse JL, Duchateau L, et al (2001) Risk factors for recurrence and metastasis after breast-conserving therapy for ductal carcinoma in- situ: Analysis of European Organization for Research and Treatment of Cancer Trial 10853. J Clin Oncol 19: $2263-2271$

29. Kerlikowske K, Molinaro A, Cha I, et al (2003) Characteristics associated with recurrence among women with ductal carcinoma in situ treated by lumpectomy. J Natl Cancer Inst 95: 1692-1702

30. Silverstein MJ, Lagios MD, Groshen S, et al (1999) The influence of margin width on local control of ductal carcinoma in situ of the breast. N Engl J Med 340: 1455-1461

31. Thomas J, Evans A, Macartney J et al (2010) Radiological and pathological side estimations of pure ductal carcinoma in situ of the breast: a review of 2564 cases from the Sloane Project. Br J Cancer 102: 285-293

32. Monteau A, Sigal-Zafrani B, Kirova YM et al (2009) Ductal carcinoma in situ of the breast with close or focally involved margins following breast-conserving surgery: treatment with reexcision or radiotherapy with increased dosage. Int J Radiat Oncol Biol Phys 75: 1021-1028

33. Radiation Therapy Oncology Group (2004) RTOG 98-04. Phase III trial of observation _/- tamoxifen vs. RT _/- tamoxifen for good risk ductal carcinoma in situ (DCIS) of the female breast. September

34. Leonard G, Swain S (2004) Ductal Carcinoma in situ, complexities and challenges. J Natl Cancer Inst 96: 906-920 
35. Hughes LL, Wang M, Page DL (2009) Local excition alone without irradiation for ductal carcinoma in situ of the breast: a trial of the Eastern Cooperative Oncology Group. J Clin Oncol 27: 5319-5324

36. Harris JR (2005) Radiotherapeutic Considerations for DCIS. American Society of Clinical Oncology. 2005 Educational Book $41^{\text {st }}$ Annual Meeting May 13-17, 2005. pp 69-74

37. Vincens E, Alves K, Lauratet B, et al (2008) Margin status in ductal carcinoma in situ of the breast. Bulletin du Cancer. 95: 1155-1159

38. Mokbel K, Cutuli B (2006) Heterogeneity the ductal carcinoma in situ and its effects of managements. Lancet Oncol 7:756-765

39. Morrow M (2009) Breast conservation and negative margins: hoow much is enough? Breast 18 suppl 3: S84-6

40. Dunne C, Burke JP, Morrow M et al (2009) Effect of the margin status on local recurrence after breast conservation and radiation therapy for ductal carcinoma in situ. J Clin Oncol 27: 1615-1620

41. Mansell RE (2003) Ductal Carcinoma in Situ: Surgery and Radiotherapy. Breast 12:447-450

42. Goldhirsch A, Ingle JN, Gerlber RD et al (2009) Threeholds for the therapies: highlights of the Saint Gallen International Expert Consensus, on the primary therapy of early breast cancer. Ann Oncol 20 (8): 1319-1329

43. Fisher B, Constantino J, Redmond C et al (1993) Lumpectomy compared with lumpectomy and radiation therapy for the treatment of intraductal breast cancer. N Engl J Med 328:1581-1586

44. Boughey JC, Gonzalez RJ, Bonner E et al (2007) Current treatment and clinical trial developments for ductal carcinoma in situ of the breast. Oncologist 12: 1276-1287

45. Sanders ME, Schuyler PA, Dupont MO and Page DL (2005) The natural history of low-grade DCIS of the breast in women treated by biopsy only revealed over 30 years long-terms follow-up. Cancer 103 (12): 2481-2484

46. Silverstein MJ, Lagios MD, Martino S, et al (1998) Outcome after invasive LR in patients with ductal carcinoma in situ of the breast. J Clin Oncol 16:1367-1373

47. Solin LJ, McCormick B, Recht A, et al (1996) Mammographically detected clinically occult ductal carcinoma in situ (intraductal carcinoma) treated with breast conserving surgery and definitive breast irradiation. Cancer J Sci Am 2:158-165

48. Ernster VL, Barclay J, Kerlikowske K, et al (2000) Mortality among women with ductal carcinoma in situ of the breast in the population-based Surveillance, Epidemiology and End Results program. Arch Intern Med 160:953-957

49. Lee LA, Silverstein MJ, Chung CT, et al (2006) Breast cancer specific mortality after invasive local recurrence in patients with duct carcinoma in site of the breast. Am J Surg 192:416-419

50. Fisher ER, Costantino J, Fisher B, et al (1995) Pathologic findings from the National Surgical Adjuvant Breast Project (NSABP) protocol B-17. Intraductal carcinoma (ductal carcinoma in situ). Cancer 75:1310-1319

51. Fisher E,. Land S., Seeda R., et al (2007) Pathologic variables predictive of Breast events in patients with DCIS. Am J Clin Pathol 128: 86-94

52. Mamounas E, Fisher B, Dingam J, et al (1997) Effects of breast irradiation following lumpectomy in intraductal carcinoma (DCIS): Updated results from NSABP B-17. Proc Soc Surg Oncol 50:7

53. Vicini FA, Recht A (2002) Age at diagnosis and outcome for women with ductal carcinoma in situ of the breast. A critical review of the literature. J Clin Oncol 20:2736-2744 
54. Collins LC, Achacoso N, Nekhlyudof L (2009) Relationship between clinical and pathologic features of ductal carcinoma in situ and patient age: an analysis of 657 patients. Am J Surg Path 33: 1802-1808

55. Turaka A, Freedman GM, Li T et al (2009) Young age is not associated with increased local recurrence for DCIS treated by breast-conservation surgery and radiation. J Surg Oncol 100: 25-31

56. Silverstein MJ and Buchanan C (2003) Ductal carcinoma in situ: USC/Van Nuys Prognostic Index and the impac of margin status. Breast 12: 457-471

57. Farante G, Zurrida S, Galimberti V et al (2010) No more axillary dissection in patients with ductal intraepithelial neoplasia (DIN). Eur J Cancer 46: 476-478

58. Winchester DP, Menck HR, Osteen RT, et al (1995) Treatment trends for ductal carcinoma in situ of the breast. Ann Surg Oncol 2: $207-213$

59. Porembka M, Abraham RL, Sefko JA et al (2008) Factors associated with lymph node assessment in DCIS: analysis of 19882002 Seer Data. Ann Surg Oncol 15: 2709-2719

60. Bishop H, Kearins O, Lawrence G et al (2008) Significant Variation in the management of non invasive breast carcinoma in the UK: Initial findings from the Sloane Project, a UK National Prospective Audit. p 31. In Proceedings of the $9^{\text {th }}$ Annual Meeting of the American Society of Breast Surgeons. April 30 - May 4

61. Cutuli B, Lemanski C, Fourquet A et al (2009) Breast conserving surgery with or without radiotherapy vs mastectomy for ductal carcinoma in situ: French survey experience. Br J Cancer 100: 1048-1054

62. Edge SB, Sheldon DG (2003) Counterpoint: Sentinel lymph node biopsy is not indicated for ductal carcinoma in situ. J Natl Compr Cancer Network 1: 207-212

63. Pendas S, Dauway E, Giuliano R, et al (2007) Sentinel node biopsy in ductal carcinoma in situ patients. Ann Surg Oncol 7: 1520

64. Ansari B, Ogston SA, Purdie CA et al (2008) Meta-analysis of sentinel node biopsy in ductal carcinoma in situ of the breast. Br J Surg 95: 547-554

65. Intra M, Veronesi P, Mazzarol G et al (2003) Axillary sentinel lymph node biopsy in patients with pure ductal carcinoma in situ of the breast. Arch Surg 138: 309-313

66. Cody HS (2007) Sentinel Lymph node biopsy for breast cancer: Indications, contraindications, and new directions. J Surg Oncol $95: 440-442$

67. Julian TB, Land SR, Fourchette V et al (2007) Is sentinel node biopsy necessary in conservately treated DCIS? Ann Surg Oncol 14: 2202-2208

68. Yi M, Krishnamurthy S, Kuerer HM et al (2008) Role of primary tumor characteristics in predicting positive sentinel lymph nodes in patiens with ductal carcinoma in situ or microinvasive breast cancer. Am J Surg 196: 81-87

69. Dominguez F, Golshan M, Black D et al (2008) SLN biopsy is important in mastectomy for DCIS. Ann Surg Oncol 15: 268-273

70. Intra M, Rotmentz N, Mattar D, et al (2007) Unnecessary axillary node dissections in the sentinel lymph node era. Eur J Cancer 43: $2664-2668$ 
71. Mittendorf EA, Arciero CA, Guttchell V et al (2005) Core biopsy diagnosis of ductal carcinoma in situ: an indication for sentinel lymph node biopsy. Curr Surg 62: 253-257

72. El Sayed ME, Rakha WA, Reed J et al (2008) Predictive value of needle core biopsy diagnoses of lesions of uncertain malignant potential (B3) in abnormalities detected by mammographic screening. Hystopathology 53: 650-657

73. Sakr FA, Bezu R, Raoust C et al (2008) The sentinel lymph node procedure for patients with preoperative diagnosis of ductal carcinoma in situ: risk factors for unsuspected invasive disease and for metastatic sentinel lymph nodes. Int J Clin Practice 62: 1730-1735

74. Yen TW, Hunt KK, Ross MI et al (2005) Predictors of invasive breast cancer of an initial diagnosis of DCIS. A guide in the selective use of sentinel lymph node biopsy in management of DCIS. J Am Coll Surg 200: 516-526

75. Fadare O, Clement NF, Ghofrani M (2009) High and intermediate grade ductal carcinoma in situ of the breast: a comparison of pathologic features in core biopsies and excisions and an evaluation of core biopsy features that may predict a close of positive margin in the excision. Diagnostic Path 4: 26-31

76. O'Flynn EA, Morel JC, Gonzales J et al (2009) Prediction of the presence of invasive disease from the measurement of extent of malignant micro-calcifications on mammography and ductal carcinoma in situ grade at core biopsy. Clin Radiol 64: 178-183

77. Doyle B, al-Mudhaffer M, Kennedy MM et al (2009) Sentinel Lymph node biopsy in patients with a needle core biopsy diagnosis of ductal carcinoma in situ: is it justified? J Clin Path 62: 534-538

78. Murphy CD, Jones JL, Hughes Javid S et al (2008) Do sentinel node micrometastases predict recurrence risk in ductal carcinoma in situ and ductal carcinoma in situ with microinvasion? Am J Surg 196: 566-568

79. Moore K, Sweeney K, Wilson M, et al (2005) Outcomes for women with DCIS and positive sentinel Node: a multi-institutional audit. Ann Surg Oncol 14: 2911-2917

80. Tunon-de-Lara C, Giard S, Buttarelli M et al (2008) Sentinel node procedure is warranted in ductal carcinoma in situ with high risk of occult invasive carcinoma treated by mastectomy. Breast J 14: 135-140

81. Leidenius M, Salmenkivi K, von Smitten K et al (2006) Tumour-positive sentinel node findings in patients with ductal carcinoma in situ. J Surg Oncol 94: 380-384

82. NIH State-of-the-Science Conference Statement (2009) Diagnosis and management of DCIS. September 22-24

83. Bryan J, Land S, Allred C et al (2003 DCIS: evidence from randomized trials. Proc of the $8^{\text {th }}$ International Conference March 12-15, 2003. St Gallen, Switzerland. The Breast 12, sup 1: ppS9 (S24)

84. Bijker N, Meijnen P, Peterse JL, et al (2006) Breast-conserving treatment with or without radiotherapy in ductal carcinoma in situ: ten-year results of European Organisation for Research and Treatment of Cancer Randomized Phase III Trial 10853 - A Study by the EORTC Breast Cancer Cooperative Group and EORTC Radiotheraphy Group. J Clin Oncol 24: 3381-3387

85. Houghton J, George WD, Cuzick J, et al (2003) UK Coordinating Committee on Cancer Research: Radiotherapy and tamoxifen in women with completely excised ductal carcinoma in situ of the breast in the UK, Australia, and New Zealand: randomised controlled trial. Lancet 362: 95-102

86. Emdin SO, Grandstrand B, Ringberg A, et al (2006) SwDCIS: Radiotherapy after sector resection for ductal carcinoma in situ of the breast. Results of a randomized trial in a population offered mammography screening. Acta Oncol 45: 536-543 
87. Goodwin A, Parker S, Ghersi D et al (2009) Post-operative radiotherapy for ductal carcinoma in situ of the breast. Cochrane Database of Systematic Reviews (4) CD 000563

88. Wong JS, Kaelin CM, Troyan SL, et al (2006) Prospective study of wide excision alone for ductal carcinoma in situ of the breast. J Clin Oncol 24 (7): 1031-1036

89. Solin LJ (2006) Is excision alone adequate treatment for low-risk ductal carcinoma in situ of the breast? J Clin Oncol 24: 10171019

90. Silverstein M, Retch A, Lagios M et al (2009) Image-detected breast cancer: State-of-the-art diagnosis and treatment. Am College of Surg 209: 504-520

91. Nccn.org/professionals/physician_gls/breast.pdf. (2009)

92. Omlin A, Amichetti M, Azria D et al (2006) Boost radiotherapy in young women with DCIS: a multicentre, retrospective study of the Rare Cancer Network. Lancet Oncol, 7: 652-656

93. Azria D, Auvray H, Barillot I et al (2008) Ductal carcinoma in Situ: role of the boost. Cancer Radioterapie 12: 571-576

94. Smith B, Douglas A, Buchholz et al (2009) Accelerated partial breast irradiation consensus statement from the American society for radiation oncology (ASTRO). Int J Rad Oncol Biol Phys 74: 987-1001

95. Keisch M, Vicini F, Beitsch P et al (2009) American Society of Breast Surgeons Mammosite Radiation Therapy System registry trial: Ductal carcinoma in situ subset analysis-4 year data in 194 treated lesions. Am J Surg 198: 505-507

96. Petit JY, Veronesi U, Orecchia R et al (2009) Nipple sparing mastectomy with nipple areola intraoperative radiotherapy: 1001 cases of a five years experience at the European Institute of Oncology in Milan (EIO). Breast Cancer Res Treat 117: 333-338

97. Garcia-Etienne C, Cody III H, Dosa J et al (2009) Nipple-sparing mastectomy: initial experience at the Memorial SloanKettering cancer Center and a comprehensive review of literature. Breast J 15: 440-449

98. Brachtel E, Rusby E, Michaelson J, et al (2009) Occult nipple involvement in breast cancer: clinicopathologic findings in 319 consecutive mastectomy specimens. J Clin Oncol 27: 4930-4932

99. Barnes NLP, Boland G, Davenport A, et al (2003) A prospective study of estrogen and progesterone receptor status in ductal carcinoma-in-situ. Breast Cancer Res Treat 82: S34 (suppl 1)

100. Decensi A, Robertson C, Viale G et al (2003) A randomized trial of low-dose tamoxifen on breast cancer proliferation and blood estrogenic biomarkers. J Natl Cancer Inst 95(11): 779-790

101. Decensi A, Gandini S, Serrano D, et al (2007) Randomized dose - ranging trial of tamoxifen at low doses in hormone replacement therapy users. J Clin Oncol 25(27): 4201-4209

102. Vogel VG, Costantino JP, Wickerham DL, et al (2006) Effects of tamoxifen vs raloxifene on the risk of developing invasive breast cancer and other disease outcomes: The NSABP Study of Tamoxifen and Raloxifene (STAR) P-2 trial. JAMA 295: $2727-2741$

103. Yen TW, Hunt KK, Mirza NQ, et al (2004) Physician recomendations regarding tamoxifen and patien utilization of tamoxifen after surgery for ductal carcinoma in situ. Cancer 100: 942-949

104. Howell A. and Buzdar A (2005) Are Aromatase Inhibitors Superior to Antiestrogens? J Ster Biochem \& Molec Biol 93: 237 - 
105. Subbaramaiah K, Norton L, Gerald W, et al (2002) Cyclooxygenase-2 is overexpressed in HER-2/neu-positive breast cancer: Evidence for involvement of AP-1 and PEA3. J Biol Chem 277: 18649-18657

106. Half E, Tang XM, Gwyn K, et al (2002) Cyclooxygenase-2 expression in human breast cancers and adjacent ductal carcinomas in situ. Cancer Res 62:1676-1681

107. Lowenfels A (2008): Ductal carcinoma in situ: evolving strategies to optimal Diagnosis and management. Proceedings of the $93^{\text {rd }}$ Annual Clinical Congress of the American College of Surgeons...XXX (manca pagina)

108. Neoadjuvant Herceptin for Ductal Carcinoma in Situ of the Breast. (2008) Clinical Trials Gov identifier NCT00496808

109. Altundag K (2005) Challenge in the Treatment of Estrogen-Receptor-Negative Ductal Carcinoma in Situ. J Clin Oncol 23 (2): 357-367

110. Chan KC, Knox WF, Gee JG et al (2002) Effect of Epidermal Growth Factor Receptor Tyrosine Kinase Inhibition on Epithelial Proliferation in Normal and Premalignant Breast. Cancer Res 62: 122-128

111. Newby JC, Johnston SR, Smith IE et al (1997) Expression of epidermal growth factor receptor and c-erbB2 during the development of tamoxifen resistance in human breast cancer. Clin Cancer Res 3: 1643-1651

112. Noguchi Y, Jungbluth A, Richards EC and Old LJ (1996) Effect of interleukin 12 on tumor induction by 3-methylcholanthrene. Proc. Natl Acad. Sci. 93: 11798-11801

113. Iinuma T, Homma S, Noda T, et al (2004) Prevention of gastrointestinal tumours based on adenomatous polyposis coli gene mutation by dendritic cell vaccine. J Clin Invest 113: 1307-1317

114. Greiner J W, Zeytin H, Anver MR and Schlom J (2002) Vaccine-based therapy directed against carcinoembryonic antigen demonstrates antitumor activity on spontaneous intestinal tumors in the absence of autoimmunity. Cancer Res 62: 6944-6951

115. Xia J, Tanaka Y, Koido S et al (2003) Prevention of spontaneous breast carcinoma by prophylactic vaccination with dendritic/tumor fusion cells. J Immunol 170: 1980-1986

116. Quaglino E (2004) Concordant morphologic and gene expression data show that a vaccine halts HER-2/neu preneoplastic lesions. J Clin Invest 113: 709-717

117. Nanni P, Pupa SM, Nicoletti G et al (2000) p185(neu) protein is required for tumor and anchorage-independent growth, not for cell proliferation of transgenic mammary carcinoma. Int J Cancer 87: 186-194

118. Czerniecki BJ, Koski GK, Koldowsky U et al (2007) Targeting Her-2/new in early breast cancer development using dendritic cells with staged interleukin-12 burst excretion Cancer Res 64:1842-1852

119. Liang K, Jin W, Lu Y et al (2003) Targeting Her2 as an approach for sensitizing breast cancer cells to radiotherapy. Proc Am Assoc Cancer Res 44: 155

120. De Cicco C, Pizzamiglio M, Trifirò G, et al (2002) Radioguided occult lesion localisation (ROLL) and surgical biopsy in breast cancer. Technical aspects. Q J Nucl Med Jun 46 (2): 145-151 